\title{
CYTOLOGICAL STUDY OF NASAL SMEAR IN ALLERGIC RHINITIS
}

\author{
Bibhuti Das ${ }^{1}$, Surajeet Basumatari ${ }^{2}$
}

${ }^{1}$ Registrar, Department of ENT, FAAMCH, Barpeta, Assam.

${ }^{2}$ Associate Professor, Department of ENT, FAAMCH, Barpeta, Assam.

\begin{abstract}
BACKGROUND

Allergic rhinitis is defined clinically by a combination of two or more nasal symptoms; runny nose, blocked nose, itching, and sneezing, when occur as a result of IgE-mediated inflammation following exposure to allergen. Its characteristic feature is local accumulation of inflammatory cells including $\mathrm{T}$ lymphocytes, mast cells, eosinophils, basophils and neutrophils. Nasal cytology is a very useful diagnostic tool in diagnosing nasal allergic disorders which allows clinicians to detect the cellular modifications of the nasal epithelium caused by exposure to either physical or chemical, acute or chronic irritations and to evaluate the different types of inflammation.

Aims- 1. To study the presence of eosinophils in nasal smear of patients with Allergic Rhinitis. 2. To establish the diagnostic importance of eosinophils in nasal smear of patients with Allergic Rhinitis.
\end{abstract}

\section{MATERIALS AND METHODS}

This hospital-based descriptive comparative study was conducted in the Department of ENT, Fakhruddin Ali Ahmed Medical College and Hospital, Barpeta, Assam from July 2016 to April 2017 in 40 patients of allergic rhinitis diagnosed on the basis of history \& clinical features typical of allergic rhinitis. A control group of 40 patients who were non-allergic were also included in the study.

\section{RESULTS}

Cytological evaluation of nasal smear of patients in both the study group and control group revealed that $82.5 \%$ cases in the study group had eosinophils in their nasal smear cytological examination. 95\% cases in the control group had no eosinophilia. Only 2 cases i.e. $5 \%$ cases had slight eosinophilia. Histopathological examination of biopsy specimen of nasal polyp in 8 cases revealed that all the 8 cases had eosinophils of different grades in their biopsy tissues.

\section{CONCLUSION}

The study concluded that there exists a strong correlation between nasal smear eosinophilia and allergic rhinitis ( $p$ value less than 0.0001 which is extremely statistically significant). Nasal smear cytology is a simple, non-invasive, cost effective test to determine the presence or absence of eosinophils in allergic rhinitis and allergic nasal polyps and can be applied routinely as a reliable and inexpensive OPD tool in diagnosing allergic rhinitis where other sophisticated laboratory investigations are not readily available.

\section{KEYWORDS}

Allergic Rhinitis, Nasal Smear, Eosinophilia.

HOW TO CITE THIS ARTICLE: Das B, Basumatari S. Cytological study of nasal smear in allergic rhinitis. J. Evolution Med. Dent. Sci. 2017;6(57):4222-4226, DOI: 10.14260/Jemds/2017/916

\section{BACKGROUND}

Allergic rhinitis is defined clinically by a combination of two or more nasal symptoms; runny, blocking, itching and sneezing, when occur as a result of IgE-mediated inflammation following exposure to allergen. ${ }^{1}$ Allergic rhinitis is one of the commonest immunologic disease experienced by humans. The management of allergic rhinitis constitutes a large proportion of day-to-day practice of otolaryngologists as well as general practitioners.

Although frequently trivialised by patients and doctors, it remains a common cause of morbidity, social embarrassment and impaired performance at workplace. Allergic rhinitis is a global health problem and is increasing in prevalence. ${ }^{2,3}$

Financial or Other, Competing Interest: None.

Submission 11-06-2017, Peer Review 06-07-2017,

Acceptance 11-07-2017, Published 17-07-2017.

Corresponding Author:

Dr. Bibhuti Das,

C/o. Amiya Kumar Das,

House No. 143, Saurav Nagar,

Beltola, Guwahati -781028,

Kamrup Metro, Assam.

E-mail: drbibhutidas9@gmail.com

DOI: $10.14260 /$ jemds $/ 2017 / 916$
A characteristic feature of allergic inflammation is local accumulation of inflammatory cells including $\mathrm{T}$ lymphocytes, mast cells, eosinophils, basophils and neutrophils. ${ }^{1}$ Release of various mediators from these cells is responsible for the symptoms of allergic rhinitis which can be divided into early or delayed (late) phase response. Early phase response is mainly due to mediators released from degranulation of mast cells following exposure to an antigen. This antigen binds to mast cell bound IgE. Major mediators released are histamine, prostaglandin, thromboxane $\mathrm{A} 2$, bradykinin and platelet activation factor, etc. Accumulation of additional inflammatory cells such as eosinophils and $\mathrm{T}$ cells occurs through chemokine attraction. These cells then release additional mediators such as eosinophil cationic protein and major basic protein, which promote a second inflammatory effect approximately 3-6 hours after allergen exposure and known as delayed allergic response. ${ }^{4}$

Nasal cytology is a very useful diagnostic tool in diagnosing nasal allergic disorders. ${ }^{5,6}$ The technique allows clinicians to detect the cellular modifications of the nasal epithelium caused by exposure to either physical or chemical, acute or chronic irritations. ${ }^{7,8}$ Also, it makes it easy to 
evaluate the different types of inflammation (viral, bacterial, fungal or parasitical). ${ }^{9,10}$

Nasal cytology was introduced in 1889, when Gollash highlighted the presence of numerous eosinophils in the nasal secretions of an asthmatic patient and suggested that these cells could be the key elements for the pathogenesis of the disease. ${ }^{11}$ Eyermann, in 1927, detected the presence of granulocyte eosinophils in the nasal secretions of allergic patients and showed their importance in diagnosing the disease. ${ }^{12}$

Over the past few years, nasal cytology has shown to be quite an attractive tool in clinical and scientific applications. It has attributed to the identification of specific cellular subsets related to different nasal pathologies. ${ }^{13,14,15}$ This consideration has opened the way to the routine use of nasal cytology in the study of allergic and non-allergic, infectious and inflammatory rhinitis. Moreover, this method is simple, safe, non-invasive and poorly expensive, it could be routinely used in outpatient clinics at all ages, even in children. ${ }^{16}$

\section{Aims of the Study}

- To study the presence of eosinophils in nasal smear of patients with allergic rhinitis.

- To establish the diagnostic importance of eosinophils in nasal smear of patients with allergic rhinitis.

\section{MATERIALS AND METHODS}

This hospital-based descriptive comparative study was conducted in the Department of ENT Fakhruddin Ali Ahmed Medical College and Hospital, Barpeta, Assam from July 2016 to April 2017 in patients of allergic rhinitis diagnosed clinically after fulfilling inclusion and exclusion criteria. The patients were diagnosed on the basis of history \& clinical features typical of allergic rhinitis which included sneezing, rhinorrhoea, nasal itching and nasal obstruction. A control group of 40 patients who were non-allergic were also included in the study.

\section{Inclusion Criteria}

1. Patients above the age group of 15 years irrespective of gender, demographic profile, and socioeconomic status were included in the study.

2. Patients with clinical features which include combination of two or more nasal symptoms; runny, blocking, itching, and sneezing for more than 4 consecutive weeks.

3. Patients who were not treated with steroid in the past.

\section{Exclusion Criteria}

1. Patients with signs of super-imposed nasal infection.

2. Patients on anti-allergic treatment like antihistaminics and topical or systemic steroids.

3. Patients who is a known case of asthma on treatment or with chronic illness.

4. Previous surgical operations involving the nose and paranasal sinuses.

During the course of study 64 patients of allergic rhinitis presented to the OPD but 53 patients fulfilled the inclusion and exclusion criteria. All the 53 patients were diagnosed based on the history \& clinical features typical of allergic rhinitis. Patient's demographic and clinical data including the presence or absence of a family history for atopic symptoms were also recorded on standard questionnaire forms.

All the cases underwent nasal smear examination for eosinophil count, absolute eosinophil count, skin-prick test (to determine the allergic state on the volar part of the forearm with a standard battery of common aeroallergens) and biopsy in 8 cases of nasal polyp. But only 40 patients presented with all investigation reports and hence 40 cases were included in the study group.

Control group consisted of 40 individuals, with age and sex match with the study group. The control group was recruited with their voluntary consent from the outpatient clinic of ENT departments who came for ailments or surgical procedures other than nasal symptoms and symptoms related to allergy.

\section{Nasal Smear Examination}

Anterior rhinoscopy was performed, after application of a local vasoconstrictor (xylometazoline $0.1 \%$ ). The smears were collected by scraping the mucous membrane of the inferior meatus with a cotton applicator and smear was made on a glass slide. The slide was air dried and fixed with absolute alcohol. The slide was stained with $1 \mathrm{~mL}$ WrightGiemsa stain for $10 \mathrm{~min}$., and then rinsed with distilled water and air dried. The slide was then stained with $2 \mathrm{~mL}$ haematoxylin and eosin for $5 \mathrm{~min}$., then rinsed with distilled water and air dried. The slide was then studied under high power magnification of light microscope and eosinophil per hundred leucocytes was calculated.

\begin{tabular}{|c|c|}
\hline Grading & Eosinophil Count \\
\hline No eosinophilia & $<5 \%$ eosinophils \\
\hline Slight eosinophilia & $5-10 \%$ eosinophils \\
\hline Moderate eosinophilia & $>10 \%$ but $<50 \%$ eosinophils \\
\hline Severe/Marked eosinophilia & $>50 \%$ eosinophils \\
\hline \multicolumn{2}{|c|}{ Table 1. Scale to Interpret Nasal Smear Eosinophilia } \\
\hline
\end{tabular}

Absolute eosinophil count was also performed. A reference range of 40 to 440 cells per microlitre is considered as normal absolute count for eosinophils. Any value above this reference range is labelled as eosinophilia. Peripheral blood smears were studied using Leishman's stain. Nasal polyps were surgically removed under general anaesthesia. For histological examination, nasal polyp samples were fixed in $10 \%$ formalin, embedded in paraffin, cut with the rotary microtome into $5-\mu \mathrm{m}$ sections. Histological examination was performed using a light microscope after staining the sections with haematoxylin and eosin stain. Eosinophils in the surface layer in each section were counted and calculated the average number of eosinophils per HPF. In biopsy, cellular grading was done as follow: Mild = grade $1=$ few cells $(5-15$ eosinophils) per HPF, Moderate $=$ grade $2=$ moderate number of cells (16-49 eosinophils) per HPF, Severe = grade 3 = many eosinophils ( $>50$ eosinophils/HPF) and eosinophils in clumps.

\section{Statistical Analysis}

Data were analysed statistically in GraphPad Software 2017 Inc version. Age of the patients in both study and control group were arranged with mean age with standard deviation. The interpretation of results of nasal smear in both study and control group were evaluated by $p$ value calculated by 
Fisher's exact test to know the significance of the study. Association between absolute eosinophil count and nasal smear eosinophilia was established by using chi-square test and $p$ value. Sensitivity and specificity of the nasal smear examination and skin-prick test was done manually to correctly identify the true positive rate and true negative rate respectively.

\section{RESULTS}

This hospital-based descriptive comparative study was conducted in the Dept. of ENT, FAAMCH, Barpeta with a study population of 40 cases after fulfilling inclusion and exclusion criteria and a control group of 40 patients.

\begin{tabular}{|c|c|c|}
\hline & Study Group & Control Group \\
\hline Mean age \pm S.D & $\begin{array}{c}28.65 \pm 10.24 \\
\text { years }\end{array}$ & $\begin{array}{c}32.42 \pm 9.02 \\
\text { years }\end{array}$ \\
\hline Sex Ratio (Male: Female) & $17: 23$ & $21: 19$ \\
\hline \multicolumn{2}{|c|}{ Table 2. Patients' Profile } \\
\hline
\end{tabular}

The study population comprised of patients above the age group of 15 years. Maximum number of patients belonged to the age group of $24-35$ years and least number of patients belonged to the age group above 55 years. The mean age was 28.65 years with standard deviation (S.D.) of 10.24. Similarly, the mean age of control group with standard deviation was $32.42 \pm 9.02$ years. There were 17 males and 23 females in the study group while there were 21 males and 19 females in the control group.

\begin{tabular}{|c|c|c|}
\hline Clinical Features & No. of Patients & $\%$ of Patients \\
\hline Sneezing & 37 & 92.5 \\
\hline Itching in the nose & 18 & 45 \\
\hline Runny nose & 40 & 100 \\
\hline Nasal obstruction & 21 & 52.5 \\
\hline Nasal polyp & 8 & 20 \\
\hline
\end{tabular}

The study shows that $100 \%$ cases had runny nose followed by sneezing in $92.5 \%$ cases, nasal obstruction in $52.5 \%$ cases, itching in the nose in $45 \%$ cases and nasal polyposis in $20 \%$ cases.

\begin{tabular}{|c|c|c|c|c|}
\hline \multirow[t]{2}{*}{ Grade of Eosinophilia } & \multicolumn{2}{|c|}{$\begin{array}{l}\text { Study Group } \\
(n=40)\end{array}$} & \multicolumn{2}{|c|}{$\begin{array}{l}\text { Control } \\
\text { Group }\end{array}$} \\
\hline & No. & $\%$ & No. & $\%$ \\
\hline $\begin{array}{c}\text { No eosinophilia } \\
(<5 \% \text { eosinophils })\end{array}$ & 7 & 17.5 & 38 & 95 \\
\hline $\begin{array}{l}\text { Slight eosinophilia } \\
\text { (5-10\% eosinophils }\end{array}$ & 12 & 30 & 2 & 5 \\
\hline $\begin{array}{c}\text { Moderate eosinophilia } \\
(>10 \% \text { but }<50 \% \text { eosinophils })\end{array}$ & 17 & 42.5 & 0 & \\
\hline $\begin{array}{l}\text { Severe/Marked eosinophilia } \\
\text { (> } 50 \% \text { eosinophils) }\end{array}$ & 4 & 10 & 0 & \\
\hline & \multicolumn{4}{|c|}{$\begin{array}{c}\text { P value }<0.0001 \text { (extremely } \\
\text { statistically significant) }\end{array}$} \\
\hline
\end{tabular}

Cytological evaluation of nasal smear of patients in both the study group and control group revealed that 33 cases i.e. $82.5 \%$ cases in the study group had eosinophils in their nasal smear cytological examination. 7 cases $(17.5 \%)$ had less than $5 \%$ nasal eosinophilia. $42.5 \%$ cases had moderate eosinophilia followed by $30 \%$ cases with slight eosinophilia and $10 \%$ cases with severe eosinophilia. $95 \%$ cases in the control group had less than $5 \%$ nasal eosinophilia (no eosinophilia). Only 2 cases i.e. $5 \%$ cases were with slight eosinophilia. $\mathrm{P}$ value is less than 0.0001 (Extremely statistically significant).

\begin{tabular}{|c|c|c|c|c|}
\hline & \multicolumn{2}{|c|}{ Study Group } & \multicolumn{2}{|c|}{ Control Group } \\
\hline & $\begin{array}{c}\text { No. of } \\
\text { Patients }\end{array}$ & $\begin{array}{c}\% \% \text { of } \\
\text { Patients }\end{array}$ & $\begin{array}{c}\text { No. of } \\
\text { Patients }\end{array}$ & $\begin{array}{c}\% \% \text { of } \\
\text { Patients }\end{array}$ \\
\hline $\begin{array}{c}\text { Present } \\
\left(>440 / \mathrm{mm}^{3}\right)\end{array}$ & 36 & 90 & 3 & 7.5 \\
\hline $\begin{array}{c}\text { Absent } \\
\left(<440 / \mathrm{mm}^{3}\right)\end{array}$ & 4 & 10 & 37 & 92.5 \\
\hline & \multicolumn{4}{|c|}{$\begin{array}{c}\text { P value }<0.0001 \\
\text { (extremely statistically significant) }\end{array}$} \\
\hline $\begin{array}{r}\text { Table } 5 . \\
\text { Cc }\end{array}$ & $\begin{array}{l}\text { ripheral } \\
\text { t in Stud }\end{array}$ & $\begin{array}{l}\text { lood Absc } \\
\text { and Cont }\end{array}$ & $\begin{array}{l}\text { Ite Eosinc } \\
\text { l Group }\end{array}$ & \\
\hline
\end{tabular}

While correlating nasal smear eosinophilia with peripheral blood absolute eosinophil count, it was found that 36 cases $(90 \%)$ in study group had absolute eosinophil count (AEC) more than $440 / \mathrm{mm}^{3}$ (significant) while $7.5 \%$ cases in control group had AEC more than $440 / \mathrm{mm}^{3}$. Chi- square value equals 54.484 and $\mathrm{P}$ value is less than 0.0001 (extremely statistically significant).

\begin{tabular}{|c|c|c|}
\hline Grade of Eosinophils & No. of Patients & \% of Patients \\
\hline $\begin{array}{c}\text { Grade } 0 \\
\text { Grade } 1 \\
\text { (5-15 eosinophils/HPF) }\end{array}$ & 0 & - \\
\hline $\begin{array}{c}\text { Grade } 2 \\
(16-49 \text { eosinophils/HPF) }\end{array}$ & 5 & 25 \\
\hline $\begin{array}{c}\text { Grade } 3 \\
\text { (> 50 eosinophils/HPF) }\end{array}$ & 1 & 12.5 \\
\hline \multicolumn{2}{|c|}{ Table 6. Histology of Biopsy } \\
\hline \multicolumn{2}{|c|}{ Specimen of Nasal Polyp (n=8) } \\
\hline
\end{tabular}

In our study, it was seen that 8 cases had nasal polyp. All 8 cases had undergone histopathological examination of biopsy specimen of nasal polyp. It was observed that all the 8 cases had eosinophils of different grades in their nasal polyp biopsy tissues. $62.5 \%$ cases had grade 2 eosinophilia followed by $25 \%$ cases had grade 1 eosinophilia and 12.5 cases had grade 3 eosinophilia.

\begin{tabular}{|c|c|c|c|}
\hline \multirow{2}{*}{$\begin{array}{c}\text { Skin } \\
\text { Test }\end{array}$} & Nasal Smear & \multirow{2}{*}{$\begin{array}{c}\text { Sensitivity }=88.6 \% \\
\text { Specificity }=25 \%\end{array}$} \\
\cline { 2 - 3 } Positive & 24 & 4 & Negative \\
\hline Negative & 3 & 4 & \\
\hline \multicolumn{3}{|c|}{ Table 7. Correlation between Skin Test vs. Nasal Smear } \\
Test \\
\hline
\end{tabular}


Correlation between nasal smear test and skin prick test was analysed. It was observed that 24 patients (87.8\%) had positive nasal smear as well as skin test. 4 patients had positive skin test but negative nasal smear test. 3 patients had positive nasal smear test but negative skin test while 4 patients had both negative nasal smear test and skin test.

\section{DISCUSSION}

This hospital-based descriptive comparative study was conducted to study the presence of eosinophils in nasal smear of patients with allergic rhinitis and to establish the diagnostic importance of eosinophils in nasal smear of patients with allergic rhinitis.

Our study had 40 patients in the study group and equal number of subjects in the control group. Study group comprised of patients above 15 years with mean age of $28.65 \pm 10.24$ years. Control group had mean age of $32.42 \pm 9.02$ years. Harshvardhan et al in their study had mean age of 31.14 years and 29.63 years in study group and control group respectively..$^{17}$ Sood et $\mathrm{al}^{18}$ found the mean age of the study group to be 28.02 years which is close to our study.

The study group included 17 males and 23 females. The sex ratio is 1: 0.739 . Harshvardhan et al ${ }^{17}$ in their study had sex ratio of $1: 1.5$. However, Sood et al ${ }^{18}$ had $45 \%$ males and $55 \%$ females in their study.

While analysing the clinical features of the subjects in the study group, it was seen that $100 \%$ cases had runny nose followed by sneezing in $92.5 \%$ cases, nasal obstruction in $52.5 \%$ cases, itching in the nose in $45 \%$ cases and nasal polyposis in $20 \%$ cases. Vaidya et al ${ }^{19}$ found that $96 \%$ cases had runny nose followed by sneezing in $90 \%$ cases, pale mucosa in $80 \%$, itching and nasal obstruction in $50 \%$ cases each.

Cytological evaluation of nasal smear of patients in both the study group and control group revealed that 33 cases i.e. $82.5 \%$ cases in the study group had eosinophils in their nasal smear cytological examination. 7 cases $(17.5 \%)$ had less than $5 \%$ nasal eosinophilia. $42.5 \%$ cases had moderate eosinophilia followed by $30 \%$ cases with slight eosinophilia and $10 \%$ cases with severe eosinophilia. 95\% cases in the control group had less than 5\% nasal eosinophilia (no eosinophilia). Only 2 cases i.e. 5\% cases had slight eosinophilia.

The correlation between Allergic Rhinitis and nasal eosinophilia was first emphasised by Eyermann in 1927 who reported a series of 92 cases with $72 \%$ showing eosinophils in the nasal secretions. ${ }^{12}$

Bryan et al in 1974 concluded that increased number of eosinophils are found in nasal mucosa in active allergic nasal disease. In contrast, the normal nasal cytology usually demonstrates no eosinophils. ${ }^{14}$ Bhandari et al ${ }^{20}$ in 1972 found nasal smear for eosinophil to be positive in $81.6 \%$ of cases. Miller et $\mathrm{al}^{21}$ in 1982 found positive nasal smears for eosinophil in $45 \%$ of cases and in 5\% of controls while Urmil et al 22 in 1984 reported eosinophilia in about $90 \%$ of cases. In the study of Takwoingi et $\mathrm{al}^{23}$ in 2003 , they found the rate of nasal eosinophilia as $76 \%$. In a study conducted by Sood in 2005 , positive nasal smear for eosinophilia was found in about $80 \%$ of cases and only in $5 \%$ of controls. ${ }^{18}$

Correlation between nasal smear eosinophilia and peripheral blood absolute eosinophil count was studied and it was found that 36 cases (90\%) in study group had absolute eosinophil count (AEC) more than $440 / \mathrm{mm}^{3}$ (significant) while $7.5 \%$ cases in control group had AEC more than $440 / \mathrm{mm}^{3}$. Vaidya et $\mathrm{al}^{19}$ in their study also established the correlation between nasal eosinophilia and AEC by concluding that $90 \%$ cases in the study group had AEC $>440$ / $\mathrm{mm}^{3}$. But the study conducted by Patel and Nagpal24 (2014) showed blood AEC does not contribute in diagnosis of allergic rhinitis with present standardisation of grading.

In our study, it was seen that 8 cases out of 40 patients $(20 \%)$ in the study group had nasal polyps. All the cases had undergone histopathological examination of biopsy specimen of nasal polyp. It was observed that all the 8 cases had eosinophils of different grades in their nasal polyp biopsy tissues. $62.5 \%$ cases had grade 2 eosinophilia followed by $25 \%$ cases had grade 1 eosinophilia and 12.5 cases had grade 3 eosinophilia. Vaidya et $\mathrm{al}^{19}$ found 20 cases of nasal polyp out of 50 cases of allergic rhinitis (40\%). Histopathological examinations of nasal polyps showed grade 1, grade 2 and grade 3 eosinophilia in $20 \%, 70 \%$ and $10 \%$ cases respectively. Similarly, studies by Perić et al $^{25}$ and Garín et $\mathrm{a}^{26}$ also concluded that allergic nasal polyposis patients have significant level of eosinophils in the Histopathological specimens.

While analysing the relationship between nasal smear test and skin prick test, it was found that there exists a high degree of correlation. Around 88 percent of the cases had both the tests positive, thereby being complimentary to each other and further substantiating the diagnosis of allergic rhinitis. Also, a few false positive and false negative cases, 3 and 4 respectively were also seen. The sensitivity of the test is $88.6 \%$ and specificity was $25 \%$. This observation is similar to the findings of the study made by Sood. ${ }^{18}$ Romero et al observed that correlation between nasal smear test and skin prick test existed in $72 \%$ cases. $^{27}$

\section{CONCLUSION}

This hospital-based descriptive comparative study conducted on 80 subjects ( 40 patients in study group and 40 cases in control group) concluded that there exists a strong correlation between nasal smear eosinophilia and allergic rhinitis. Nasal smear cytology is a simple, non-invasive, cost effective test to determine the presence or absence of eosinophils in allergic rhinitis and allergic nasal polyps. It has a good correlation with blood AEC, skin prick test and histological findings in allergic nasal polyps. Hence, nasal smear cytological test can be applied routinely as a reliable and inexpensive OPD tool in diagnosing allergic rhinitis where other sophisticated laboratory investigations are not readily available. However, detailed history taking and complete physical examination must be carried out along with interpretation of nasal smear cytological test for diagnosis of allergic rhinitis.

\section{REFERENCES}

[1] Scadding G, Durhum S. Allergic rhinitis. In: Browning G. edr. Scott-Brown's Otorhinolaryngology, head and neck surgery. $7^{\text {th }}$ edn. London: 2008; p. 1386.

[2] Aberg N, Hesselmar B, Aberg B, et al. Increase of asthma, allergic rhinitis and eczema in Swedish school children between 1979 and 1991. Clinical and Experimental Allergy 1995;25(9):815-9. 
[3] Leynaert B, Neukirch F, Demoly P, et al. Epidemiologic evidence for asthma and allergic rhinitis comorbidity. Journal of Allergy and Clinical Immunology 2000;106(Suppl 5):S201-S5.

[4] Jirapongrananuruk O, Vichyanond P. Nasal cytology in the diagnosis of allergic rhinitis in children. Ann Allerg Asthma Immunol 1998;80(2):165-70.

[5] Bogaerts PA, Clement PA. The diagnostic value of a cytogram in rhinopathology. Rhinology 1981;19(4):203-8.

[6] Malmberg H, Holopainen E. Nasal smear as a screening test for immediate-type nasal allergy. Allergy 1979;34(5):331-7.

[7] Gluck U, Gebbers J0. Cytopathology of the nasal mucosa in smokers: a possible biomarker of air pollution? Am J Rhinol 1996;10(1):55-7.

[8] Boysen M, Zadig E, Digernes V, et al. Nasal mucosa in workers exposed to formaldehyde: a pilot study. Br J Indust Med 1990;47(2):116-21.

[9] Gelardi M, Tomaiuolo M, Cassano M, et al. Epstein-Barr virus induced cellular changes in nasal mucosa. Virol J 2006;3:6.

[10] Bickmore JT. Nasal cytology in allergy and infection. Otorhinolaryngology Allergy 1978;40:39-46.

[11] Gollash H. Fortschr Med 1889;7:361-5.

[12] Eyermann CH. Nasal manifestations of allergy. Ann Otol Rhinol Laryngol 1927;36:808-15.

[13] Hansel FK. Observation on the cytology of the secretions in allergy of the nose and paranasal sinuses. J Allergy 1934;5(4):357-66.

[14] Bryan MP, Bryan WT. Cytologic diagnosis in allergic disorders. Otolaryngol Clin North Am 1974;7:637-66.

[15] Gelardi M, Fiorella mL, Tarasco E, et al. Blowing a nose black and blue. Lancet 2009;373(9665):780.

[16] Gelardi M, Incorvaia C, Passalacqua G, et al. The classification of allergic rhinitis and its cytological correlate. Allergy 2011;66(12):1624-5.

[17] Ankle HNR. Nasal smear for eosinophilia: a diagnostic marker for allergic rhinitis. International Journal of Advanced Research and Review 2016;1(1):21-5.
[18] Sood A. Diagnostic significance of nasal eosinophilia in allergic rhinitis. Ind J Otolaryngol Head Neck Surg 2005;57(1):13-16.

[19] Vaidya KA, Pai S, Nagaraj TS, et al. A study on utility of nasal smear examination in diagnosing allergic rhinitis and its histopathological correlation in allergic nasal polyps. International Journal of Basic and Applied Medical Sciences 2015;5(1):291-7.

[20] Bhandari CM, Baldwa VS. Relative value of peripheral blood, nasal secretion and tissue eosinophilia in diagnosis of different patients of allergic rhinitis. Ann Allergy 1976;37(4):280-4.

[21] Miller RE, Paradise JL, Friday GA, et al. The nasal smear for eosinophils. Its value in children with seasonal allergic rhinitis. Am J Dis Child 1982;136(11):1009-11.

[22] Urmil G, Bazaz-Malik G, Mohindra SK. Significance and comparison of blood, nasal secretion and mucosal eosinophils in nasal allergy. Indian J Pathol Microbiol 1984;27(1):27-32.

[23] Takwoingi Y, Akang E, Nwaorgu G, et al. Comparing nasal secretion eosinophil count with skin sensitivity test in allergic rhinitis in Ibadan, Nigeria. Acta Otolaryngologica 2003;123(9):1070-4.

[24] Patel AK, Nagpal TP. Comparison of blood absolute eosinophil count and nasal smear eosinophils with symptoms and severity of clinical score in patients of allergic rhinitis. Indian Journal of Allergy Asthma and Immunology 2014;28(2):74-7.

[25] Perić A. Inflammatory mediators in allergic rhinitis and nasal polyposis. Arhiv za Higijenu Rada i Toksikologiju 2011;62:341-8.

[26] Garín L, Armengot M, Alba JR, et al. Correlations between clinical and histological aspects in nasal polyposis. Acta Otorrinolaringológica Española 2008;59(7):315-20.

[27] Romero JN, Scadding G. Eosinophilia in nasal secretions comparedto skin prick test and nasal challenge test in the diagnosis of nasal allergy. Rhinology 1992;30(3):169-75. 